\title{
ENCUESTAS DE OPINIÓN PÚBLICA Y DERECHO A LA INFORMACIÓN VERAZ
}

\author{
LUIS GÁLVEZ MUÑOZ \\ Profesor de Derecho Constitucional \\ Universidad de Murcia
}




\section{SUMARIO}

1. INTROdUCCIÓN. 2. El debate Regulación legal VS. AutorRegulación PRofesioNAL. A) La tesis de la autorregulación. B) Consideraciones críticas. C) Conclusión. 3. EL ESTADO DE LA LEGISLACIÓN. A) Los sistemas comparados. $B$ ) El Derecho español. a) El régimen franquista. b) La transición democrática. c) El régimen actual. C) Valoración. 


\title{
ENCUESTAS DE OPINIÓN PÚBLICA Y DERECHO A LA INFORMACIÓN VERAZ
}

POR

\author{
LUIS GÁLVEZ MUÑOZ \\ Profesor de Derecho Constitucional \\ Universidad de Murcia
}

\section{INTRODUCCIÓN}

Desde que el hálito democrático anida en el corazón del ser humano, una pregunta se alza de forma recurrente en cada ocasión en que un problema político o social ha inquietado a la población en general o a sus responsables políticos: ¿qué opinan los ciudadanos sobre el mismo?

Si en el pasado la respuesta a esta pregunta estaba sujeta al albur de las impresiones puramente personales, fruto de la propia experiencia y de las creencias individuales de cada uno, hoy día contamos -gracias a muchos investigadores, pero sobre todo al tesón y genialidad de George Gallup - con un instrumento de medida sumamente fiable y cuyo grado de utilización resulta apabullante: las encuestas de opinión pública'.

1 Sobre el origen y desarrollo de las encuestas de opinión pública vid. George Gallup, The Sophisticated Poll Watcher's Guide, Princeton Opinion Press, 1972; Elio Brusati, I sondaggi elettorali e dell'opinione pubblica, Doxa, Pavia, 1995, págs. 7-15; Jean Stoetzel y Alain GIRARD, Las encuestas de opinión pública, traduc- 
Su carácter científico es difícil de negar, a pesar de todo lo que digan sus muchos detractores ${ }^{2}$. La sabia y prudente combinación, depurada a lo largo de muchos años, del método representativo, de la teoría de la probabilidad, de la ley de los grandes números y de la técnica del cuestionario, permiten conocer con un alto grado de exactitud y certidumbre, las actitudes de una sociedad determinada ante los problemas que se le plantean, así como el impacto que en la misma tienen los más diversos acontecimientos nacionales e incluso internacionales.

Los sondeos de opinión, siempre que se realicen con el rigor adecuado, son un verdadero instrumento científico, porque se apoyan sobre principios teóricos firmes que han sido suficientemente contrastados con la realidad. Como decía el gran sociólogo francés Jean Stoetzel:

«El rigor y la precisión de las encuestas están probados. La práctica confirma lo bien fundadas que están. Porque esta práctica nóes fruto de una invención ingeniosa. Deriva de una teoría perfectamente establecida y demostrable. Cada una de las operaciones sobre las que se basa el resultado de una encuesta se apoya en una teoría... La encuesta es científica porque cada gesto que implica, para ser acertado, se apoya en una teoría. La teoría, de todos modos, no basta por sí misma. Las encuestas han progresado gracias a la con-

ción al español de Eloy Fuente Herrero, Instituto de Opinión Pública, Madrid, 1973, págs. 55-74 ledición original: Les sondages d'opinion, Presses Universitaires de France, París, 1973); Louis Harris, "Polls and policies in the United States", Public Opinion Quarterly, vol. 27, 1963, págs. 3-18; Tom W. SMITH, "The first straw? A study of the origins of election polls", Public Opinion Quarterly, vol. 54, 1990, págs. 609626; Alfred $\mathrm{MAX}_{\mathrm{A}}$ La république des sondages, Gallimard, París, 1981, págs. 7-8, 6775; Jean-Jacques Droesbeke, Bernard Fichet y Philippe TASsı (eds.), Les sondages, Économica, 1987, págs. 3-17; George GaLluP y Saw RAE, The pulse of democracy, Simon and Shuster, New York, 1940; Claude E. Robinson, Straw votes: a study of political predicting, Columbia University Press, New York, 1932; y Charles N. Roul y Albert H. CANTRIL, Polls: their use and misure in politics, Basic Books, New York, 1972.

2 Para conocer las críticas a la figura de los sondeos de opinión, en general, y electorales, en particular, vid. Alexandre LAZAREFF, Le droit des sondages politiques. Analyse de la réglamentation française, Librairie Generale de Droit et de Jurisprudence, París, 1983, págs. 16-18; Jean Stoetzel y Alain GIRARD, Las encuestas de..., op. cit., págs. 23-27; Alain LANCELOT, "Sondage d'opinion et suffrage universel", Commentaire, núm. 10, 1980, págs. 214-219; José I. WeRT OrTEGA, Carta a un incrédulo sobre las encuestas y su muy disputado crédito, Península, Barcelona, 1996, passim; Maurice Druon, "A propos des sondages", Le Monde, de 5-6 de septiembre de 1972; Comunicado de los institutos franceses Ifot y Sofres de 22 de septiembre de 1972 (Apud Sondages. Revue Française de..., op. cit., págs. 47-48); y Dominique de Montvalon, "Sondages: la peur des chiffres", Le Point, de 16 de mayo de 1977. 
frontación permanente entre los hechos y los resultados de la observación» 3 .

No es, sin embargo, de los fundamentos científicos de las encuestas de opinión pública de lo que queremos tratar en este trabajo; y no solo porque tal cometido excedería con mucho de nuestras limitadas capacidades e incluso de nuestras inquietudes profesionales, sino sobre todo porque existe una amplísima bibliografía especializada que se ocupa de ello más que adecuadamente ${ }^{4}$.

Nuestro objetivo es muy distinto. Consiste, pura y simplemente, en examinar, desde un punto de vista estrictamente jurídico, uno de los muchos y graves problemas que las encuestas de opinión pública plantean a la democracia: la garantía de su objetividad, es decir, de la calidad, seriedad y rigor en la realización y publicación de las mismas.

La constante - casi diaria- realización de encuestas de opinión pública y su presencia habitual en los medios de comunicación y la relevancia del derecho a la información veraz en nuestro sistema constitucional, en combinación con factores como la indudable influencia que ejercen sobre las decisiones de los responsables políticos y sobre las actitudes y comportamientos de los ciudadanos en general, la posibilidad de que cualquier persona o entidad, con independencia de los medios o cualificación con que cuente, pueda realizar un sondeo, o la facilidad de manipulación de sus resultados, justifican sobradamente, a nuestro juicio, el interés del tema abordado.

3 Vid. Jean Stoetzel y Alain Girard, Las encuestas de..., op. cit., págs. 103-104.

4 La bibliografía sobre la metodología de las encuestas es inabarcable. Relacionarla, siquiera en sus elementos más destacados, ocuparía varias págs. de esta obra y no tendría gran utilidad, salvo para los propios especialistas en la materia. Nos vamos a limitar, por ello, a citar algunas de las más generales y asequibles: European Societr for Opinion and Marketing Research (ESOMAR), Guía de los sondeos de opinión, edición inglesa preparada por John O'BRIEN, Asociación Española de Estudios de Mercado, Marketing y Opinión (AEDEMO), Barcelona, 1993; EuRoPEAN SoCIETy for Opinion and MARKeting Research (ESOMAR), Cómo interpretar y publicar los resultados de las encuestas. Guía para profesionales de los medios de comunicación, Asociación Española de Estudios de Mercado, Marketing y Opinión (AEDEMO), Barcelona, 1989; José I. Wert OrTega, Carta abierta a..., op. cit. ; Elisabeth Noelle-Neumann, Encuestas en la sociedad de masas. Introducción a los métodos de la Demoscopia, traducción de Eloy Fuente Herrero, Alianza Editorial, Madrid, 1970 (edición original: Umfrnagen in der Massengesellschaft. Einführung in die Methoden der Demoskopie, Rowohlt Taschenbuch Verlag GmbH, Reinbek y Hamburg, 1963); Elio Brusati, I sondaggi..., op. cit.; y Jean Stoetzel y Alain GiRARD, Las encuestas de..., op. cit. 


\section{EL DEBATE REGULACIÓN LEGAL VS. AUTORREGULACIÓN PROFESIONAL}

\section{A) La tesis de la autorregulación}

La contención de la actividad normativa del Estado en materia de elaboración y publicación de encuestas de opinión pública, en favor de la autorregulación profesional, es una demanda generalizada entre quienes intervienen profesionalmente en el proceso de realización y difusión de las mismas: los investigadores sociales, las empresas de sondeos, los periodistas y los medios de comunicación.

Ahora bien, con independencia de los apoyos personales con que cuente esta tesis, lo que nos interesa conocer por encima de todo, es su fundamento, esto es, los motivos de justificación habitualmente alegados a favor de la autorregulación. Éstos pueden resumirse, aun con riesgo de simplificar en exceso, en los dos que se citan a continuación, cada uno de los cuales opera, es oportuno tenerlo en cuenta, de forma independiente respecto del otro:

a) El primero, anclado en la más pura ideología liberal, consiste en poner de relieve la falta de madurez democrática que demuestra el establecimiento de cualesquiera normas jurídicas en el proceso de realización y difusión de las encuestas de opinión, dada su estrecha conexión con el derecho a la libertad de expresión, "una de las conquistas más preciosas y más frágiles de la democracia", en expresión de Alexandre Lazareff5.

La realización y difusión de sondeos de opinión pública forma parte, como es lógico, del derecho a la libertad de expresión, entendiendo este término en su sentido más amplio, como comprensivo no sólo de la libertad de manifestar libremente las propias ideas y opiniones, sino también de la libertad de información y de producción científica; y se considera, desde una posición maximalista de este derecho, que cualquier intento de proceder a la regulación jurídica de la forma de obtener o publicar los resultados de las encuestas de opinión, existiendo la vía de la autorregulación profesional, es contrario al espíritu de una sociedad auténticamente libre $y$, por tanto, inconveniente, cuando no, pura y simplemente, inconstitucional. El Estado tiene que limitarse a aplicar en este ámbito específico las normas jurídicas generales de defensa de la competencia y de exigencia de responsabilidad

5 Vid. Alexandre Lazareff, Le droit des...., op. cit., pág. 23. 
civil contractual y ante terceros; no debe ir más allá e indicar a los organismos de sondeos y a los medios de comunicación cómo deben elaborar y publicar las encuestas de opinión.

Esta postura liberal se ha manifestado con especial virulencia en relación con la posibilidad de prohibir la publicación de encuestas electorales durante los últimos días del período preelectoral, una medida que, entre otros muchos objetivos, trata de hacer posible la rectificación, antes de la votación, de las deficiencias e irregularidades que puedan tener los sondeos que se publiquen durante la fase anterior del período preelectoral ${ }^{6}$. En todos los países en que la cuestión se ha planteado ha habido manifestaciones frontales, vehementes $y$ viscerales de rechazo. No obstante, por mucho que busquemos no hallaremos palabras más expresivas de esta concepción absolutista del derecho a la libertad de expresión que aquellas con las que Edward HEALTH, destacado dirigente del partido conservador británico durante muchos años, puso fin a la polémica desatada en su partido, tras la inesperada derrota de 1966, sobre la necesidad o conveniencia de prohibir o no la publicación de los sondeos electorales en tiempo de elecciones:

¿¿Prohibir los sondeos? Claro que no. No se puede hacer en un país libre»?.

6 Sobre esta tesis vid. José L. DADER, "Aspectos deontológicos y legales de las encuestas", en Alejandro MuÑoz Alonso y otros, Opinión pública y comunicación política, Eudema, Madrid, 1990, pág. 543; intervención del profesor Juan J. SolazÁBAL ECHEVARRIA en el debate que sobre la reforma del régimen electoral tuvo lugar en el Centro de Estudios Constitucionales el 31 de enero de 1994 (recogidos en José R. Montero Gibert y otros, La reforma del régimen electoral, Centro de Estudios Constitucionales, Madrid, 1994, pág. 108; y Carta abierta a un incrédulo sobre las encuestas y su muy disputado crédito, Península, Barcelona, 1996, pág. 170); Augusto CERRI, "Manifestazione del pensiero, opinione pubblica e sondaggi elettorali", en Vincenzo ZeNO-ZeNCOVICH (ed.), I sondaggi di opinione ed elettorali. Profili giuridici e metodologici, Centro di Iniziativa Giuridica Piero Calamandrei y Jovene Editore, Napoli, 1985, pág. 91; Jean-Claude MASCLET, Droit électoral, Presses Universitaires de France, París, 1989, pág. 242; Pierre HuET, "L'esperienza francese», en Vincenzo ZENo-Zencovich (ed.), I sondaggi..., op. cit., pág. 50; y Alfred MAX, La république des..., op. cit., pág. 154.

7 Apud Monique Charlot, La democratie à l'anglaise. Les campagnes électorales en Grande-Bretagne depuis 1931, Armand Colin, París, 1972, pág. 418. En este mismo sentido vid. Rafael LóPEz PINTOR, "Opinión pública y encuestas de opinión en España", Revista de Derecho Político, núm. 14, 1982, págs. 119-120 (también en La opinión pública española. Del franquismo a la democracia, Centro de Investigaciones Sociológicas, Madrid, 1982); Robert WORCESTER, «Proposal for regulating or banning the taking of publication of opinion polls", Paper to the Parliamentary Assembly of the Council of Europe, 26 de noviembre de 1984; EUROPEAN SOCIETY FOR OPInion and MaRketing Research (ESOMAR), Cómo interpretar y....., op. cit., pág. 39; Mi- 
b) El segundo argumento utilizado en apoyo de la autorregulación tiene un carácter más práctico $y$ funcional. Hace referencia a las ventajas que en términos de eficacia, esto es, de protección efectiva de los derechos y valores en cuestión, ofrece la autorregulación de los profesionales afectados frente a la normativa impuesta por el Estado.

La complejidad y el dinamismo del proceso de realización de los sondeos de opinión pública y de interpretación de sus resultados, la rigidez que entraña toda regulación legislativa y el mayor grado de agilidad y flexibilidad de los códigos deontológicos y sus aplicadores, son algunos de los argumentos utilizados habitualmente por muchos autores para poner de relieve la existencia de grandes dificultades prácticas a la hora de definir $y$ hacer respetar las normas jurídicas que se tuvieran a bien establecer en este ámbito.

Consideran, por ello, que no puede haber mejor control sobre las encuestas de opinión pública que el asumido y ejercido libremente por los propios sujetos implicados en su desarrollo. Así se ha manifestado, entre otros, el profesor italiano Ernesto Bettinelli, quien, ante el dilema entre regulación legislativa y por vía convencional, decide optar por la segunda posibilidad "por su flexibilidad asi como por su idoneidad para prestarse a experimentaciones $y$, por tanto, a sucesivas adaptaciones" 8 .

Ésta es también la opinión de otro compatriota suyo, Carlo ERMINERO, quien se ha manifestado con gran contundencia al respecto. He aquí sus coloquiales $y$ expresivas palabras:

"El instituto de investigación tiene una responsabilidad contractual frente a su cliente... pero no es de esta responsabilidad de la que quiero hablar, porque la misma está tutelada por normas generales... Hay también una responsabilidad extracontractual respecto a quien usa los resultados de una encuesta porque los lee en alguna parte. Y puede ser fácilmente engañado por sondeos mal hechos o mal presentados. El problema es entonces la tutela de los terceros, de quien lee, de quien tiene conocimiento de sus resultados. Estoy convencido de que a) esta tutela es hoy peligrosamente débil y

chel BruLÉ, L'empire des sondages: transparence ou manipulation?, Robert Laffont, París, 1988, pág. 223; y Wolfgang DoNSBACH, "Foreword from Esomar", en NisI RoME (ed.), The freedom to publish opinion polls. Report on a Worldwide study, ESOMAR, Amsterdam, 1997, pág. 4.

8 Vid. Ernesto BettinelLI, “Diritto di voto, libertá di propaganda e regolamentazione dei sondaggi elettorali", en Vincenzo ZENO-ZENCOVICH (ed.), I sondaggi..., op. cit., págs. $68-69$. 
que b) hay que intervenir urgentemente porque aunque no ha habido todavía incidentes graves, podria haberlos. ¿Y qué forma de tutela debería establecerse? Mi opinión es contraria a la disciplina legislativa. Cuanto menos intervenga el legislador en este terreno mejor. Tengo miedo del legislador, tengo miedo de los juristas que lo aconsejan, tengo miedo del ejecutivo, que estaría inevitablemente encargado de aplicar una posible ley de sondeos... La ley tendería inevitablemente a cristalizar ciertas normas, ciertos procedimientos. $Y$ esto es peligrosísimo, porque la investigación se está desarrollando, mejorándose a sí misma a través de la experiencia y el conocimienton?.

\section{B) Consideraciones críticas}

La tesis de la contención legislativa estatal en el ámbito de las encuestas de opinión pública, en beneficio de la autorregulación por parte de los profesionales directamente implicados en su realización y publicación, no nos parece de ningún modo digna de aceptación.

El motivo es simple y directo: las razones que apoyan la autorregulación profesional son bastante débiles y pueden ser salvadas con cierta facilidad a poco que se analicen con espíritu crítico, como vamos a ver a continuación.

a) El primer argumento utilizado por los partidarios de la autorregulación, el que sugiere una falta de madurez democrática por parte de quienes defienden la intervención legislativa en este terreno, no tiene la más mínima base y es posible rechazarlo de plano. A pesar de que durante mucho tiempo ha sido un lugar común en el ámbito jurídico-político identificar toda regulación del derecho a la libertad de expresión con posturas totalitarias y poco respetuosas con los valores de la democracia pluralista, nada se halla, a nuestro juicio, más lejos de la realidad ${ }^{10}$.

9 Vid. Carlo Erminero, "ll sondaggio tra libertà e autodisciplina», en Vincenzo ZENO-ZENCOVICH (ed.), I sondaggi di opinione....., op. cit., págs. 205-206. En el mismo sentido vid. también Gustavo GHIDINI, "La responsabilità dei mass-media nella diffusione dei sondaggi", en Vincenzo ZENO-ZENCOVICH (ed.), I sondaggi di opinione..., op. cit., págs. 111-113; y José I. Wert ORTEGA y Rafael López PINTOR, "Polls and politics: an empirical history of misunderstanding", en la obra colectiva, Seminar on Opinion polls (Sevilla, España, febrero 1989), European Society for Opinion and Marketing Research (ESOMAR), Amsterdam, 1989 (Apud José L. DADER, "Aspectos deontológicos y..., op. cit., pág. 541).

10 Sobre este punto vid. José L. DADER, "Aspectos deontológicos...", op. cit., págs. 541-545. 
El derecho a la libertad de expresión es, ciertamente, uno de los pilares fundamentales de toda sociedad democrática, al que el Ordenamiento Jurídico de los distintos países occidentales concede el más elevado rango constitucional, pero cuyo ejercicio puede, en ocasiones, poner en peligro otros derechos $y$ valores constitucionalmente protegidos, algunos de los cuales no son de menor importancia que aquél para el buen funcionamiento de las instituciones democráticas.

En estos casos, la necesidad de regular, en mayor o menor grado, el ejercicio de la libertad de expresión, con el fin de hacerlo compatible con el de otros intereses constitucionales en juego, se presenta con toda crudeza; y es que no existen, como es sabido, derechos absolutos, derechos que carezcan de límites en su ejercicio.

La esencia de la democracia consiste, precisamente, en una integración de diferentes derechos, bienes y valores merecedores de protección, con exigencias a menudo contradictorias, y a las que es obligado dar satisfacción en el máximo grado en que sea posible hacerlo, lo que, lógicamente, se resuelve en inevitables limitaciones recíprocas. La vida democrática implica, en definitiva, la regulación de las libertades con el fin de garantizarlas ${ }^{11}$.

El profesor Giuseppe Contini ha expresado esta tesis general con singular y notable maestria:

"Toda sociedad con aspiraciones democráticas, cuanto más se desarrolla, tanto más aumenta sus exigencias y entre éstas, ciertamente no la última, la de disponer cada vez de mayores espacios de libertad. Esto comporta, sin embargo, paradójicamente, que al crecimiento de la libertad corresponda un aumento de los límites que se le imponen, con el fin de permitir a todos un óptimo disfrute: lo que comporta, por consiguiente, que en el ámbito del ordenamiento las diferentes instituciones juridicas deban limitarse reciprocamente, para que puedan coexistir en una ordenada coexistencia civil (C. Const. Sent. n.120, de 8 de julio de 1957). De hecho, aumentando la exigencia de libertad y debiéndose ésta entender, no como mera abstracción, sino como elemento indispensable para la supervivencia de la misma sociedad civil, resulta que el poder público debe hacerse cargo de asegurar a todos, sobre una base igualitaria, cuando menos tendencialmente, no el mero principio de li-

11 Así lo ha señalado reiteradamente el Tribunal Constitucional a partir de su Sentencia 11/1981, de 8 de abril. Vid., por ejemplo, las Sentencias 2/1982, de 29 de enero; la 110/1984, de 26 de noviembre; 13/1985, de 31 de enero; la 53/1986, de 5 de mayo; 196/1987, de 11 de diciembre; 37/1989, de 15 de febrero; y 120/1990, de 27 de junio. 
bertad, sino más bien el uso concrèto de ésta, llegando, cuando sea indispensable, a limitar legislativamente el mismo ejercicio de ciertos derechos de libertad" 12 .

No se trata, por tanto, como sostienen los críticos de la regulación del derecho a la libertad de expresión, de un enfrentamiento entre afirmación de la libertad y negación de la misma, sino, más bien, por utilizar las expresiones acuñadas por el profesor Giuseppe Contini, de la opción entre "libertad libre» y «libertad regulada»13.

Desde esta perspectiva, y entrando en el terreno de las encuestas de opinión pública, el reconocimiento constitucional de que goza el derecho a recibir información veraz y la relevancia que tiene en la garantía institucional de la formación de una opinión pública libre, legitiman sobradamente, a nuestro juicio, por lo menos en el plano de los principios, la regulación de esta materia14.

En este sentido, José L. Dader, destacado defensor de la opción legislativa, ha podido declarar con contundencia lo siguiente:

«Por lo demás, la supuesta colisión entre libertad de expresión y control legal de los sondeos es tan inconsistente como pensar que las normas legales para la defensa de los consumidores sea un atentado ilegítimo contra la libertad de comercio. Resulta paradójico que unas mismas personas consideren progresistas las exigencias de etiquetado para evitar las adulteraciones de los productos de consumo y en cambio estimen retrógrado las garantías de etiquetado del producto informativo fácilmente corruptible que contienen las encuestas. Ante las simpatías acríticas que despierta cualquier canto demagógico a la libertad cabría recordar que los defensores más enfervorizados de la libertad de comercio siempre han sido... los piratas" 15 .

12 Vid. Giuseppe ContinI, "Profili giuridici della regolamentazione dei sondaggi elettorali e spunti comparatistici", en Vincenzo ZeNO-ZENCOVICH (ed.), I sondaggi di opinione....., op. cit., pág. 13.

13 Vid. Giuseppe ContINI, “Profili giuridici...», op. cit., pág. 15.

14 Sobre la relevancia institucional del artículo 20 de la Constitución hay una abundante jurisprudencia. Vid., fundamentalmente, las Sentencias del Tribunal Constitucional 6/1981, de 16 de marzo; 12/1982, de 31 de marzo; 104/1986, de 17 de julio; 159/1986, de 16 de diciembre; 165/1987, de 27 de octubre; 107/1988, de 8 de junio; 20/1990, de 15 de febrero; y 176/1995, de 11 de diciembre.

15 Vid. José L. DADER, "Aspectos deontológicos...", op. cit., págs. 544-545. En parecidos términos vid. también su artículo "Sondeos electorales e ignorancia de la ley", El Pais, de 30 de octubre de 1984. 
b) En cuanto al argumento más relevante en defensa de la autorregulación privada, el de las mayores ventajas que presenta la misma frente a la regulación legal, hay que decir que, aunque en la teoría parece convincente, existen una serie de elementos que lo desvirtúan en la práctica y lo hacen inatendible.

La autorregulación presenta graves problemas para asegurar la calidad y rigor en el proceso de realización y difusión de encuestas de opinión pública. Pueden resumirse en los seis siguientes.

1. La falta de una voluntad clara, sincera y decidida de los profesionales por autorregularse. No es ésta una afirmación meramente subjetiva, sino que se apoya en diversos datos de la realidad. Ante todo, en el hecho de que las iniciativas de autorregulación en la materia tan sólo han tenido culminación en el ámbito de los investigadores sociales y de los institutos de sondeos, y no en el de los periodistas y los medios de comunicación ${ }^{16}$. Los "libros de estilo" de que se han dotado muchos medios de comunicación, algunos de los cuales contienen referencias específicas a la presentación de los sondeos de opinión, se presentan como las únicas normas constrictivas al respecto ${ }^{17}$.

Pero no se trata sólo de esto. Es que, además, los códigos aprobados tienen un grado de generalidad y ambigüedad bastante eleva$\operatorname{dos}^{18} ; y$, por si fuera poco, las distintas tentativas de disciplina profesional realizadas hasta la fecha y las adhesiones generalizadas a las mismas sólo han surgido como reacción al riesgo de puesta en marcha de iniciativas de regulación legislativa o al hecho mismo de su establecimiento ${ }^{19}$. Esto ha ocurrido en todos los países del mundo; incluso

16 Vid. Alexandre LAZAREFF, Le droit des....., op. cit., pág. 37. Sobre esta cuestión nos hemos ocupado con mayor detalle en un trabajo anterior. Vid. Luis Gálvez MuÑoz, "La objetividad de las encuestas de opinión pública: ¿autocontrol o control legal?", Comunicación presentada en el Congreso Derechos constitucionales y Estado Autonómico, celebrado en Tarragona los días 20-22 de octubre de 1999.

17 Vid., por ejemplo, el Libro de Estilo El País, 11. a edición, El País, Madrid, 1996, pág. 28, epigrafe 1.38 .

18 Vid. José L. DADER, "Aspectos deontológicos...", op. cit., págs. 537.

19 Así se manifiestan, entre otros, Emmanuel Derieux, "Droit et déontologie des sondages d'opinion", Trimedia, núm. 10, 1980, págs. 10 y 11; Alexandre LAZAREFF, Le droit des..., op. cit., pág. 90; y Jean CHARLOT en los debates producidos durante el Segundo Congreso Interuniversitario de politólogos francófonos, celebrado en Lieja el 22 de abril de 1975 (Apud Jean Beaufays (ed.), Sondage et opinion politique. Ilè Rencontre Interuniversitaire des Politistes Francophones, Liège, 22 avril 1975, Université de Liège, Liège, 1975, pág. 94). En contra vid. Michel BruLÉ, L'empire des..., op. cit., pág. 127. 
en los que tienen mayor tradición de autorregulación. Así sucedió, por ejemplo, en los Estados Unidos en los años cuarenta, donde la avalancha de iniciativas legislativas, tanto a nivel estatal como federal, en orden a la regulación de las encuestas de opinión pública, en general, y de las encuestas electorales en particular, llevaron a la Asociación Americana para el Estudio de la Opinión Pública (AAPOR: American Association for Public Opinion Research) a ponerse a trabajar sobre el asunto y presentar su primer proyecto de código de ética profesional, aunque no fue finalmente adoptado por sus asociados hasta $1960^{20}$.

2. El alcance esencialmente limitado de la autorregulación, pues los códigos deontológicos que aprueben las distintas organizaciones profesionales existentes no obligarían, por propia definición, más que a sus miembros, es decir, a los profesionales que voluntariamente se integren en las mismas, lo que desafortunadamente, como la práctica demuestra, no sucede en todos los casos ${ }^{21}$.

En España, por ejemplo, hay muchas personas y organizaciones públicas y privadas que hacen encuestas de opinión pública, pero no están todas integradas en una organización nacional o internacional de carácter corporativo. El caso más llamativo sería el del Centro de Investigaciones Sociológicas (CIS), que es, con mucho, la entidad que más encuestas realiza en orden a medir las opiniones y las actitudes de los españoles en materia política y social.

3. La insuficiencia de los códigos de autorregulación estatuidos hasta el momento presente para garantizar su propia efectividad. El establecimiento de un código de ética profesional es, ciertamente, en sí mismo, un hecho positivo, pero no garantiza, por sí sólo, su cumplimiento. Es necesario, además, la creación de instancias de autocontrol capaces de imponer sanciones a los infractores; $y$ esto es algo que no ha sucedido todavia.

Y así lo ha puesto de relieve el profesor José L. Dader:

«Los códigos, por otro lado, sólo son una declaración de adhesión voluntaria a unos principios, pero sin una exigencia adicional de cumplimiento por ningún tipo de comité interno de las asocia-

20 El Código Ético de la American Association for Public Opinion Research (AAPOR) sigue en vigor, teniendo su última revisión fecha de marzo de 1986. Sobre el surgimiento de este Código vid. Alexandre LAZAREFF, Le droit des..., op. cit., pág. 27; y José L. DADER, "Aspectos deontológicos...", op. cit., pág. 536.

21. Así lo apuntan, por ejemplo, Alexandre LAZAREFF, Le droit des..., op. cit., pág. 36; y Michel BrulÉ, L'empire des..., op. cit., pág. 142. 
ciones profesionales. Significativamente el Código WAPOR [World Association for Public Opinion Research] de 1986 establece en su punto último que la pertenencia a la asociación implica la aceptación del código, pero no implica la garantía de la cualificación profesional del miembro. Dicho de otro modo: debe aceptarlo, lo que no significa que lo cumpla ni pueda ser obligado a hacerlo» ${ }^{22}$.

Es del todo punto evidente que para que cualquier tipo de regla social tenga eficacia y se cumpla, no basta con una pura y simple manifestación pública, por decirlo así, de buena voluntad, por parte de los afectados. Es necesario, además, tanto la previsión de sanciones gravosas en caso de incumplimiento, como, sobre todo, la imposición efectiva de las mismas cuando haya lugar a ello; y en materia de encuestas esto es algo que no suele ocurrir en ningún país $y$, por supuesto, tampoco en España, como la práctica se ha encargado de demostrar ${ }^{23}$. Falta una estructura corporativa suficiente para llevar a cabo eficazmente la tarea de autocontrol; si en el caso de las empresas de opinión esta estructura se halla en fase de institucionalización, en el ámbito de los medios de comunicáción de masas es del todo inexistente, no siendo previsible, en modo alguno, su instauración en un futuro próximo ${ }^{24}$.

4. La prohibición establecida en los ordenamientos de muchos países, como el nuestro, de los llamados "Tribunales de Honor" en el seno de las organizaciones profesionales ${ }^{25}$, lo cual hace, desde luego, difícilmente realizable la previsión e imposición, en materia de encuestas, de sanciones efectivas para los infractores de los códigos deontológicos instaurados o, cuando menos, limita sensiblemente el contenido y alcance de las mismas ${ }^{26}$.

En el mejor de los casos parece evidente, como reconoce Michel Brulé, que los medios de que dispone una asociación profesional para asegurar el cumplimiento de la disciplina de sus miembros, son menos

22 Vid. José L. DADER, "Aspectos deontológicos...", op. cit., pág. 537.

23 Ibídem. En cuanto a la actividad sancionadora desplegada en Francia por la SYNTEC, la Cámara sindical de las sociedades de estudios y sondeos, vid. Michel BRuLÉ, L'empire des..., op. cit., págs. 133-134.

24 Vid. José I. WERT ORTEGA: "Perspectivas de reforma del régimen electoral: campañas, medios de comunicación y encuestas electorales", en José R. MonTERo GIBERT y otros, La reforma del..., op. cit., pág. 108; y Carta abierta..., op. cit., pág. 145.

25 El artículo 26 de nuestra Constitución declara terminantemente: "Se prohiben los Tribunales de Honor en el ámbito de la Administración civil y de las organizaciones profesionales".

26 Vid. José L. DADER, "Aspectos deontológicos...", op. cit., pág. 542. 
poderosos que los que pudiera establecer el Estado27. Cuestión distinta es que luego las autoridades estatales encargadas de hacer cumplir la legislación establecida no ejerzan, por diferentes circunstancias, sus competencias, como ha ocurrido en cierta medida en nuestro país con la Junta Electoral Central respecto de la regulación de las encuestas electorales ${ }^{28}$.

5. La existencia de un arraigado corporativismo profesional pro persona o de trinchera, más pendiente de la defensa de los integrantes de la profesión frente al exterior que del rigor y honestidad en el ejercicio de la misma, y que hace temer por la lenidad en la aplicación, cuando no en la pura y simple inaplicación, de las distintas tareas de control que se pudieran atribuir a las oportunas instancias profesiona$\operatorname{les}^{29}$.

Esta negativa e impertinente concepción del corporativismo, que hunde sus raíces en la sociedad estamental y gremial del Antiguo Régimen, es bastante difícil de superar a corto o medio plazo, por muy firmes y claras que sean las declaraciones de los profesionales en sentido contrario. Responde a un sentimiento de autoprotección personal que está anclado en la propia esencia del ser humano, y por tanto, sujeto a una lenta y difícil evolución, sobre todo en los países latinos como el nuestro en donde los límites entre la vida pública y la vida privada son tan difíciles de trazar.

6. El riesgo, en todo caso, de que los comités de vigilancia profesional que se pudieran establecer en el seno de las organizaciones profesionales, efectuaran un ejercicio abusivo e inadecuado del poder de sanción moral de que se les dotase, dada la feroz rivalidad y competencia existente en el ámbito de las empresas de sondeos y de los medios de comunicación. La instauración de órganos de autocontrol puede ser ocasión para dar rienda suelta a enemistades o resentimientos profesionales e incluso para cortar el paso a los pequeños institu-

27 Vid. Michel Brulé, L'empire des..., op. cit., pág. 142.

28 Sobre la pasividad de la Junta Electoral Central a la hora de controlar el cumplimiento de la regulación vid. José L. DADER, «La responsabilidad pública de los periodistas ante el control social de los sondeos electorales", en Esteban López-Escobar y José L. Orinuela (eds.), La responsabilidad pública del periodista. Actas de las II Jornadas de Ciencias de la Información, Servicio de Publicaciones de la Universidad de Navarra, Pamplona, 1988, passim.

29 Vid. Pierre AvriL, "Le droit des sondages", en la obra colectiva Service public et libertés. Mélanges offertes au proffeseur Robert-Édouard Charlier, Éditions de L'Université et de L'Enseignement Moderne, París, 1981, pág. 694. 
tos de sondeos o medios de comunicación que amenacen comercialmente a los más poderosos.

A este respecto, $y$ en relación con los organismos de sondeos, ha afirmado José L. Dader:

«... Existe una evidente posibilidad, sin amparo legal ante la indefensión, de que los tribunales internos de la profesión de los encuestadores sancionaran con menor dureza a los grandes institutos comerciales representados en el comité de vigilancia, y por el contrario aplicaran decisiones más duras a pequeños institutos que amenazaran comercialmente a los primeros. Aunque tales sanciones morales o reales fueran después recurribles ante tribunales ordinarios, muy probablemente los daños causados a estas empresas o grupos profesionales competidores fueran ya irreparables»30.

\section{C) Conclusión}

A la luz de todo lo dicho es posible concluir que la regulación jurídica de la objetividad de las encuestas de opinión pública no solo es posible o legítima desde un punto de vista estrictamente constitucional, por la importancia de los derechos y valores en peligro, sino también conveniente y hasta necesaria, dada la manifiesta incapacidad de la autorregulación profesional para garantizar de forma adecuada y eficaz la calidad, el rigor y la transparencia de estas omnipresentes informaciones.

No es posible sostener con rigor la tesis de que la mejor ley en materia de encuestas de opinión pública es la que no existe. $Y$ así lo afirma también con gran claridad el profesor de Opinión Pública José L. Dader, tantas veces citado en este trabajo:

«En tales condiciones, los códigos deontológicos de los encuestadores pueden tener un valor de orientación moral, pero no capacidad correctora de los abusos o incorrecciones, cuestión ésta sólo abordable mediante legislación ordinaria»31.

El Estado no puede, en modo alguno, permanecer impasible ante los graves problemas que la falta de objetividad de los sondeos de opinión pública pueden plantear a la democracia y a los que las organizaciones profesionales no han dado, ni pueden dar tampoco, adecuada respuesta. No puede limitarse, como sugiere la Asamblea Parla- 
mentaria del Consejo de Europa por medio de su Comité de Relaciones Parlamentarias y Públicas, a aceptar y a promover la elaboración y aplicación de los códigos deontológicos en la materia ${ }^{32}$. Es necesario, por el contrario, que intervenga jurídicamente porque lo que está en juego es algo de la mayor importancia: la protección de derechos y valores fundamentales tan relevantes para el sistema constitucional como la información veraz de los ciudadanos, la correcta formación de las politicas públicas y la pureza del voto.

La regulación jurídica es el único modo eficaz de asegurar que la realización y publicación de las encuestas de opinión sea compatible con la propia autenticidad de la democracia de opinión en la que vivi$\operatorname{mos}^{33}$. Con el establecimiento de normas jurídicas en este terreno se pretende evitar que las actitudes y los comportamientos de los ciudadanos en los más diversos ámbitos de la vida pública e incluso privada puedan ser distorsionados por interpretaciones falsas de la realidad producidas por la publicación de encuestas deficientes, manipuladas o, simplemente, inventadas.

En otro caso se llegaría a la absurda situación de que los ciudadanos se creyeran cada vez más libres, dada la facilidad de conocer a cada momento, gracias a las encuestas, las opiniones $y$ conductas que vertebran la sociedad; $y$ de que, en realidad, fueran cada vez menos libres, por la absoluta falta de control externo sobre la seriedad y veracidad de dichas informaciones.

32 Las conclusiones del Informe sobre los sondeos de opinión elaborado por el Comité de Relaciones Parlamentarias y Públicas de la Asamblea Parlamentaria del Consejo de Europa son muy significativas: «4. Estudiada la cuestión, el Comité no comparte la opinión de que un reforzamiento del control [sobre los sondeos de opinión] sea deseable o necesario y considera que no ha lugar a emprender un esfuerzo de armonización internacional. 5. Estima, no obstante, que los organismos de sondeos deberían sujetarse a códigos de conducta apropiados y que los Estados miembros deberían usar su influencia con el fin de asegurar que un sistema de autorregulación (eventualmente parecido al de la Asociación Europea para los Estudios de Opinión y de Marketing) fuera aplicado por todos". Vid. Parliamentary Assembly of the Council of Europe. Committee on Parliamentary and public Relations, information report public opinion polls, Rapporteur. Sir John PAGE, Doc. 5549, de 29 de agosto de 1985, pág. 2.

33 Sobre la configuración de la democracia como régimen de opinión vid., por ejemplo, Alejandro Muñoz Alonso, Política y nueva comunicación. El impacto de los medios de comunicación de masas en la vida política, Fundesco, 1989, págs. 99 106. El tema está ya presente ya en los clásicos, como, por ejemplo, MAdison (EI Federalista), Edmund BURKe (Escritos y discurso), Alexis de TocoueVILle (La democracia en América), Jean J. Rousseau (El contrato sociah), David Hume (Tratado sobre la naturaleza humana), etc. 
Como muy bien dijo Pierre Viasson-Ponté, hace ya casi un cuarto de siglo, poco antes de la presentación en la Asamblea Nacional francesa de diversas proposiciones de ley sobre la regulación de las encuestas electorales:

«Una vez más, es preciso regular y controlar los sondeos. O renunciar a ellos» 34 .

Ahora bien, hay que tener en cuenta que la opción por la regulación jurídica de la objetividad de las encuestas de opinión pública y no por los códigos deontológicos, no supone considerar que los profesionales afectados no tengan nada que aportar al respecto. Nada se halla más alejado de nuestras intenciones; y ello por dos razones básicas y elementales:

- En primer lugar, porque en esta materia, como en cualquier otro sector de la vida social, es necesaria la activa cooperación de los destinatarios de las leyes para asegurar su adecuada efectividad. No basta con la publicación de las normas en el Boletín Oficial del Estado y con la intervención de los poderes públicos.

- En segundo término, porque no cabe desconocer tampoco que la regulación jurídica y la autorregulación profesional no son opciones incompatibles entre sí, pues es perfectamente posible, y así sucede en muchos casos, que el legislador establezca una regulación jurídica mínima y esencial en determinada materia y que ésta sea completada, con mayor o menor rigor y efectividad, por los profesionales afectados, en el ejercicio de su poder de autorregulación. La deontología profesional de los realizadores y los difusores de encuestas puede sumarse, así, con todas sus limitaciones, a las obligaciones legales, en beneficio de los ciudadanos. El Derecho no puede ni debe regularlo todo, sino sólo lo más básico e imprescindible ${ }^{35}$.

34 Vid. Pierre Vianson-Ponté, "Le Waterloo des sondages", Le Monde, 15 de marzo de 1977.

35 A la uimportancia de la autorregulación como necesario complemento de las normas públicas» en el ámbito del derecho a la información alude el profesor Marc CaRRillo en su artículo "A vueltas con la cláusula de conciencia", El País, 6 de junio de 1997. 


\section{EL ESTADO DE LA LEGISLACIÓN}

\section{A) Los sistemas comparados}

De forma paralela a las discusiones de los profesionales de las encuestas y de la información, de los especialistas en sociología, ciencia política y comunicación pública, de los políticos y de los juristas sobre la forma más adecuada de regular la objetividad de las encuestas de opinión pública, los diferentes países del mundo han ido poco a poco decantando su posición al respecto.

No ha habido, desde luego, como era de esperar, una respuesta unánime, sino más bien todo lo contrario ${ }^{36}$. La diversidad existente puede, sin embargo, sintetizarse en tres grandes grupos:

1. Confiar la disciplina de las encuestas de opinión pública en su integridad a los profesionales y empresas implicados en su realización y publicación (Estados Unidos, Reino Unido).

2. Regular únicamente las encuestas de mayor relevancia pública, es decir, las electorales, bien durante una parte más o menos prolongada del período preelectoral (Brasil), bien durante todo el año (Francia, Portugal, Italia) ${ }^{37}$. Las demás encuestas de opinión e incluso las encuestas electorales publicadas fuera del ámbito temporal legal-

36 Para un estudio en profundidad sobre el Derecho comparado en la materia vid., fundamentalmente, las siguientes obras y documentos: Alexandre LAZAREFF, Le droit des....., op. cit., págs. 25-31; Giuseppe ConTINI, "Profili giuridici...", op. cit., págs. $13-45$ (sobre todo de la 19 a la 32); José L. DADER, "Aspectos deontológicos...", op. cit., págs. 545-556; Parliamentary Assembly of the Council of Europe. CommitTeE on Parliamentary and PUblic Relations, Information report...., op. cit., págs. 3-10; Nisl Rome (ed.), The freedom to....., op. cit.; Generalitat de Catalunya. Departament de Governació, Les enquestes electorals, Collecció Quaderns Electorals, núm. 2, BarceIona, 1995, págs. 24-27; y José L. Ruiz-Navarro Pinar, "Artículo 69", en Luis M.a CAzorla Prieto (director), Comentarios a la Ley Orgánica del Régimen Electoral General, Cívitas, Madrid, 1986, págs. 640-641, si bien este trabajo recoge básicamente los datos del citado Informe del Consejo de Europa sobre los sondeos de opinión pública.

37 Francia fue el primer país del mundo que reguló las encuestas electorales durante todo el año. La regulación francesa está constituida actualmente por la Ley núm. 77-808, de 19 de julio de 1977, relativa a la publicación y a la difusión de ciertos sondeos de opinión y sus dos decretos de aplicación: de un lado, el Decreto núm. 78-79, de 25 de enero de 1978, para la aplicación de la Ley núm. 77-808, de 19 de julio de 1977, relativa a la publicación y a la difusión de ciertos sondeos de opinión; de otro, el Decreto núm. 80-351, de 16 de mayo de 1980, para la aplicación del artículo 5 de la Ley núm. 77-808, de 19 de julio de 1977, relativa a la publicación y a la difusión de ciertos sondeos de opinión. 
mente determinado en su caso, quedan confiadas a la autorregulación profesional ${ }^{38}$.

3. Regular todas las encuestas de opinión pública, tengan carácter electoral o no, y durante todo el año (Bélgica) ${ }^{39}$. Ello no impide, desde luego, que puedan establecerse algunas especifidades sobre las encuestas electorales.

\section{B) El Derecho español}

Ante las diversas actitudes existentes en los Ordenamientos de otros países respecto de la regulación jurídica de la objetividad de las encuestas de opinión pública, la pregunta que se plantea de inmediato es la de determinar qué posición ha adoptado nuestro país, esto es, en qué lugar, dentro de este rico contexto comparado, es posible ubicar a la legislación española.

Puestos en esta tarea puede resultar conveniente comenzar por indicar que España ha experimentado las tres posiciones señaladas. Lo vamos a ver a través del examen de los hitos normativos más destacados que han tenido lugar a lo largo de las diversas etapas políticas de nuestra reciente historia.

\section{a) El régimen franquista}

La existencia de un régimen político no democrático en nuestro país durante el período en el que surgieron y se consolidaron las encuestas de opinión pública, hizo que esta técnica de información adoleciera, durante todos esos negros años de nuestra historia, de un escaso grado de desarrollo. Es por eso, quizás, por lo que el primer intento de regular en España la objetividad de los sondeos de opinión pública no tuvo lugar hasta los últimos momentos del régimen fran-

38 De la influencia de las encuestas electorales, un campo de investigación clásico en la Ciencia Política que ha dado lugar a un gran acopio de bibliografía, ya nos hemos ocupado en un trabajo anterior. Vid. Luis Gálvez MuÑoz, "La influencia de las encuestas electorales sobre los electores", en Estudios de Derecho Constitucional y de Ciencia Política. Homenaje al profesor Rodrigo Fernández-Carvajal, Universidad de Murcia, 1997, págs. 797-818.

39 Vid. la Ley de 18 de julio de 1985, sobre publicación de los sondeos de opinión y otorgamiento del título de "Instituto de sondeo de opinión», según el texto modificado por Ley de 21 de junio de 1991. 
quista, cuando, con ocasión del desbordamiento de las ansias democráticas de la sociedad, las encuestas políticas comenzaron a ser noticia en la prensa periódica ${ }^{40}$.

Ese intento normativo se plasmó en el Decreto 2951/1975, de 31 de octubre, del Ministerio de Información y Turismo, sobre régimen de las empresas dedicadas a las encuestas de opinión ${ }^{41}$. Esta disposición, que encontró fuertes obstáculos para fraguarse desde dentro y fuera del Gobierno42, contenía una Exposición de Motivos que, a nuestro juicio, es irreprochable:

"Las encuestas de opinión, que han cobrado en nuestros días un auge $y$ difusión grandes, disponen de procedimientos ya decantados, aunque en continua revisión y superación, cuyo empleo requiere unos conocimientos técnicos y un montaje profesional adecuado, sin los cuales los resultados obtenidos no llegan a ser fiables e inducen, por consecuencia, a error en las conclusiones.

Parece preciso que tales encuestas se realicen en condiciones de solvencia y garantía que acrediten su fiabilidad en beneficio del público. Por ello, es aconsejable proceder a una ordenación somera de dicho sector, a fin de garantizar tanto la idoneidad de la constitución y funcionamiento de las empresas dedicadas a esta rama de actividad como las condiciones y requisitos que aseguren a los destinatarios últimos que los resultados se han obtenido con la corrección técnica debida.

En el marco del libre ejercicio de una actividad profesional legítima, se trata de establecer unas exigencias normativas elementales que prevengan actuaciones incorrectas lo mismo a favor de las propias empresas, que sufririan de otro modo una competencia desleal, que en ventaja del público, que debe operar sobre productos obtenidos rigurosamente, sin deformación, con publicidad de su origen y de la metodología utilizada».

No obstante, conviene tener muy presente que esta Exposición de Motivos no recoge las auténticas aspiraciones de los responsables de la norma aprobada. La finalidad última perseguida con el establecimiento de la regulación de las encuestas de opinión pública no era, como se afirma oficialmente, ofrecer un producto de calidad a los ciudadanos y salvaguardar el derecho a la veracidad de la información, sino,

40 Vid. Rafael LóPEZ PINTOR, "Opinión pública y encuestas...", op. cit., págs. 114 y $118-119$.

41 Vid. el Boletín Oficial del Estado núm. 284, de 24 de noviembre de 1975. 114.

42 Vid. Rafael LóPEZ PinTor, "Opinión pública y encuestas...", op. cit., pág. 
más bien, servir de barrera de protección del régimen frente a las encuestas incómodas o que no fueran de su gusto ${ }^{43}$.

El contenido del Decreto responde perfectamente a esta dualidad de intenciones, la declarada y la verdadera. Así nos encontramos con disposiciones plausibles y dignas de reconocimiento e imitación, pero también con otras muy características del régimen político que las dictaba y poco compatibles, por tanto, con los principios democráticos.

Entre las medidas más significativas establecidas en el Decreto que comentamos podemos destacar las siguientes:

1. La obligación por parte de las empresas que deseen llevar a cabo la realización de encuestas de opinión pública, de inscribirse en un Registro específico, que se llevaría en el seno del Ministerio de Información y Turismo (artículo 1).

2. La prohibición de que los medios de comunicación puedan "publicar resultados de encuestas por empresas no inscritas en el Registro o que sean contrarias, en su planteamiento o conclusiones, a los principios e Instituciones contenidos en las Leyes Fundamentales, al respeto debido a las personas que las encarnan, a las exigencias de la defensa nacional, a los derechos de las personas o a las leyes, la moral y las buenas costumbres" (artículo 5).

3. La obligación de que en la difusión de resultados de las encuestas de opinión se haga constar «de forma clara y destacada los datos esenciales que permitan la identificación de la Empresa y del patrocinador del trabajo, así como los datos técnicos que permitan una valoración real de los resultados" (artículo 6).

4. La obligación genérica de "garantía y fiabilidad técnica de la encuesta" (artículo 7.1).

5. La atribución al Ministerio de Información y Turismo tanto del control de la regulación establecida como de la sanción de las infracciones que se cometan, «sin perjuicio de la responsabilidad penal o civil que proceda" (artículos 7.1 y 8 ).

6. La obligación de los medios de difusión de proceder a la "inserción gratuita del dictamen de comprobación cuando se observen defectos de importancia" en la publicación de la encuesta (artículo 7.2).

43 Vid. José L. DADER, “Aspectos deontológicos...», op. cit., págs. 549-550. 
El Decreto 2951/1975 tuvo, sin embargo, una corta vigencia, la misma que la permanencia en el cargo de las autoridades que lo dictaron. Fue derogado el 18 de marzo de 1976 por el primer Gobierno de la Monarquía, apenas cuatro meses después de su aprobación. Se puso fin así a uno de los primeros intentos habidos en el mundo, si no el primero, de regular la objetividad de los sondeos de opinión pública. Hasta ese momento sólo se habían dictado normas prohibiendo la publicación de encuestas electorales durante todo o gran parte del período preelectoral (Japón, Brasil, Canadá, Portugal) o sobre protección de los derechos de los encuestados (Estados Unidos), pero no sobre la calidad, la honestidad y el rigor en la realización y presentación de las encuestas de opinión pública en general44.

Por lo demás, hay que tener en cuenta que en el breve plazo de tiempo en que esta norma estuvo en vigor no tuvo aplicación efectiva, debido a la falta de la mínima voluntad política y administrativa para ello, como pone de relieve el hecho de que su aprobación no fuera acompañada de las imprescindibles normas de desarrollo para hacerla valer $^{45}$.

\section{b) La transición democrática}

Tras la derogación del Decreto 2951/1975 la regulación de las encuestas de opinión pública volvió a quedar en manos de los profesionales de las encuestas y de los medios de comunicación, con las negativas consecuencias que cabía esperar de ello en un momento de crecimiento espectacular de la actividad sondeadora $y$ de ausencia de una estructura corporativa mínima que articulase unas reglas básicas $y$ elementales de autorregulación en la materia.

Estos factores condujeron al peor escenario posible: la realización de encuestas por entidades carentes de toda preparación para

44 El primer intento, aunque fallido, de regular la objetividad de las encuestas de opinión tuvo lugar en los Estados Unidos por obra del senador Gerald NYE, de Dakota del Norte. Se trataba de una Proposición de Ley en la que se exigía a los organismos de sondeos que informaran sobre el tamaño de la muestra utilizada y que conservaran todos los documentos sobre los sondeos realizados durante el plazo de dos años. Vid. Alexandre LazAReff, Le droit des....., op. cit., pág. 26.

45 Contra este Decreto se plantearon, además, dos recursos de reposición ante el Consejo de Ministros, previos a la interposición del correspondiente recurso contencioso-administrativo (apud José L. DADER, "Aspectos deontológicos...", op. cit., pág. 550). 
ello; la planificación del diseño de muchas encuestas conforme a los deseos políticos de quien la encarga; la práctica de ajustar o modificar sus resultados ante la necesidad de noticias espectaculares por parte de los medios de comunicación, sus clientes naturales tratándose de encuestas destinadas a la publicación; la creación de organismos de sondeos para operar tan sólo durante el reducido espacio de un proceso electoral y con el único objeto de sembrar dudas respecto a la veracidad de las cifras aportadas por institutos serios; e incluso la pura y simple utilización del aura científico de las encuestas para dar curso a puras y simples operaciones de marketing o propaganda.

En definitiva, el descontrol en la materia fue absoluto y las consecuencias tanto sobre la confianza en las empresas encuestadoras en general, como sobre el prestigio de la propia técnica de las encuestas de opinión y la salvaguarda del derecho a la información veraz, devastadoras.

Ante esta preocupante situación nuestros legisladores no pudieron permanecer impasibles. Los abusos producidos con ocasión de las elecciones generales de 1 de marzo de 1979, en donde se produjo una auténtica avalancha de sondeos, realizados y publicados en su mayor parte sin las mínimas garantías de seriedad y calidad, y la conciencia generalizada de la gran influencia que las encuestas tuvieron en los resultados electorales, llevaron al nuevo Parlamento, el primero constituido bajo los dictados de la Constitución de 1978, a regular de forma inmediata las encuestas con mayor repercusión pública: las encuestas electorales y las relacionadas con las consultas que se sometan a referéndum ${ }^{46}$.

Esta regulación se plasmó en dos leyes distintas, aunque estrechamente unidas: la Ley Orgánica 2/1980, de 18 de enero, sobre regulación de las distintas modalidades de referéndum y la Ley 14/1980, de 18 de abril, sobre régimen de encuestas electorales, que, aunque comenzó a tramitarse antes, se aprobó varios meses después.

46 Vid. Joaquín Garcia Morillo, "El desarrollo de la campaña", en Jorge DE Esteban y Luis LóPEz GuerRa (directores), Las elecciones legislativas de 1 de marzo de 1979, Centro de Investigaciones Sociológicas, Madrid, 1979, págs. 243-244; y José I. Wert Ortega, "Encuestas y derecho a la información", El País, 18 de diciembre de 1990, así como, también, su intervención en el debate sobre la reforma del régimen electoral que tuvo lugar en el Centro de Estudios Constitucionales el 31 de enero de 1994 (apud José R. Montero Gibert y otros, La reforma del..., op. cit., pág. 184). No obstante, este último autor considera que «en ningún caso relevante tuvo lugar un uso abusivo (en el sentido de abuso de la confianza o buena fe de los electores) que diera base objetiva a la necesidad de una intervención legislativa para limitar la publicación” (Carta abierta a..., op. cit., pág. 140). 
La primera contiene una única disposición en materia de encuestas. Se trata del artículo 15.2 que establece una breve prohibición temporal de difundir encuestas relacionadas con la consulta sometida a referéndum. Su texto dice así:

"Durante los cinco días anteriores al de la votación queda prohibida la publicación, difusión total o parcial o comentario de los elementos o resultados de cualquier encuesta o sondeo de opinión, así como las operaciones de simulación de voto realizadas a partir de sondeos de opinión, que estén directa o indirectamente relacionados con la consulta sometida a referéndum".

La segunda norma, la Ley 14/1980, es mucho más rica, pues se dedica íntegramente a regular la publicación de las encuestas electorales. Su contenido puede resumirse en los siguientes puntos ${ }^{47}$ :

1. Se limita la aplicación de la Ley a las encuestas "que estén directa o indirectamente relacionadas con un referéndum o con elecciones a Cortes, Locales, o de Comunidades Autónomas" y que, además, se publiquen "durante las campañas electorales" (artículo 1).

2. Se establece una regulación de la objetividad de las encuestas electorales bastante modesta, pues queda reducida a la obligación de publicar la ficha técnica y a la prohibición de falsificaciones (artículos 2 y 3 ).

3. Se prohíbe la publicación de encuestas electorales durante los cinco días anteriores al de la votación (artículo 7).

4. Se atribuye a la Junta Electoral Central la tarea de controlar el correcto cumplimiento de la Ley y de sancionar las infracciones que se puedan producir (artículos 3, 4 y 9 ).

5. Se impone a los medios de comunicación que hubieran publicado un sondeo violando las disposiciones de la Ley, la obligación de publicar de inmediato las rectificaciones requeridas por la Junta Electoral Central (artículo 5).

47 La Proposición de Ley de Coalición Democrática era bastante más ambiciosa que la Ley finalmente aprobada (vid. el Boletin Oficial de las Cortes Generales. Congreso de los Diputados, I Legislatura, Serie B, núm. 31-I, de 30 de mayo de 1979 , págs. 125-128). Sufrió, sin embargo, importantes modificaciones, en aras del consenso, como consecuencia del estudio y debate realizado por la Ponencia constituida en el seno de la Comisión de Presidencia. 


\section{c) El régimen actual}

Unos pocos años después, y como consecuencia de la urgente necesidad, puesta de manifiesto por el Tribunal Constitucional, de que se aprobara una Ley Electoral que sustituyera al Real Decreto-Ley 20/1977, de 18 de marzo, sobre Normas Electorales, y que recogiera, además, toda la legislación electoral de carácter general, tuvo lugar una nueva actuación legislativa en relación con las encuestas electorales: el trasvase, sin apenas modificaciones, del contenido de la Ley 14/1980, de 18 de abril, sobre régimen de encuestas electorales a la Ley Orgánica 5/1985, de 19 de junio, del Régimen Electoral General, en concreto a los artículos 69,145 y $153.2^{48}$.

La regulación efectuada por esta ley en materia de encuestas electorales tan sólo difiere de su inmediato precedente en dos aspectos de interés:

1. Se amplia el ámbito temporal de la regulación, que ya no se limita a "las campañas electorales", sino que cubre todo el período preelectoral, esto es, el lapso temporal comprendido entre el día de la convocatoria electoral y el de la celebración de las elecciones.

2. Se refuerza el régimen sancionador, pues se introduce un delito específico para sancionar la infracción dolosa de la normativa vigente en materia de encuestas electorales, manteniéndose respecto a las demás infracciones - las culposas- la potestad sancionadora de la Junta Electoral Central.

48 La decisión del Gobierno de iniciar el proceso de elaboración de la LOREG tiene su origen más inmediato en la jurisprudencia del Tribunal Constitucional, quien declaró en su Sentencia núm. 72/1984, de 14 de julio, la inconstitucionalidad de la Ley Orgánica de Incompatibilidades de Diputados y Senadores, por entender que, conforme al artículo 81 de la Constitución, la Ley electoral no podía elaborarse por partes, sino que era obligado hacerla de una sola vez. El máximo intérprete de nuestro texto fundamental afirmaba, entre otras cosas, lo siguiente: «En todos los casos en que el legislador es soberano y le corresponde la decisión de legislar o de no legislar nada le impide que la normación de una determinada materia se lleve a cabo por partes. Lo mismo puede decirse en aquellos casos que el legislar sea una obligación impuesta por la Constitución. Si la Constitución no establece lo contrario -y lo contrario ha de entenderse siempre excepcional-, corresponde a la oportunidad política decidir si la legislación se hace por partes o de una sola vez. Sin embargo, no puede aplicarse el mismo criterio a aquellos otros casos en que por las razones que fueran la Constitución establezca la unidad de legislación para una sola materia o para un conjunto de problemas y situaciones entrelazadas y próximas entre sí, sin perjuicio de que una vez establecida esta legislación pueda modificarse parcialmente" (Fundamento Jurídico núm. 5). 
Desde su aprobación, la Ley Orgánica 5/1985, de 19 de junio, del Régimen Electoral General, ha sufrido varias modificaciones, pero sólo hay una que afecta al régimen de las encuestas electorales, aunque no directamente a la objetividad de las mismas, pues tiene más que ver con el acceso de las fuerzas políticas a las encuestas de intención de voto efectuadas por los poderes públicos durante el período preelectoral, que con lo que es propiamente la garantía de seriedad, calidad y rigor de las mismas.

Se trata del apartado número 8 del artículo 69 , introducido en 1991 con el fin de asegurar la neutralidad de los poderes públicos y la igualdad de las candidaturas durante el proceso electoral, y cuyo tenor literal dice así:

"En el supuesto de que algún organismo dependiente de las Administraciones Públicas realice en período electoral encuestas de intención de voto, los resultados de las mismas, cuando así lo soliciten, deben ser puestos en conocimiento de las entidades políticas concurrentes a las elecciones en el ámbito territorial de la encuesta en el plazo de cuarenta y ocho horas desde la solicitud» 49 .

La última actuación legislativa en relación con la objetividad de las encuestas de opinión pública se produjo muy poco tiempo después de la modificación de la LOREG de 1991 y supuso un importante cambio en la actitud del legislador. Si en los años ochenta las autoridades normativas se habian preocupado exclusivamente de las encuestas electorales que son objeto de publicación durante un corto período de tiempo anterior a la votación, ahora se interesan también por otro tipo de encuestas: las que se incorporen a la instrucción de un procedimiento administrativo ${ }^{50}$.

49 En relación con este nuevo precepto es de gran importancia la consulta de la Instrucción de la Junta Electoral Central, de 26 de abril de 1993, de desarrollo del artículo 69 de la Ley Orgánica 5/1985, de 19 de junio, del Régimen Electoral General (BOE núm. 101, del 28 de abril).

50 Durante los años noventa se han aprobado normas relativas a las encuestas de opinión, pero no en relación con su objetividad, que es lo que aquí nos interesa estudiar. Por ejemplo, el artículo 30 de la Ley Orgánica 5/1992, de 29 de octubre, de regulación del tratamiento automatizado de datos de carácter personal, recientemente derogada, contenía una referencia específica a los ficheros de titularidad privada relativos a encuestas e investigaciones, con el fin de proteger los derechos de los encuestados: " 1 . Sólo se utilizarán de forma automatizada datos de carácter personal en las encuestas de opinión, trabajos de prospección de mercados, investigación científica o médica y actividades análogas, si el afectado hubiera prestado libremente su consentimiento a tal efecto. 2. Los datos de carácter perso- 
Así lo pone de manifiesto la aprobación del artículo 78.2 de la Ley 30/1992, de régimen jurídico de las Administraciones Públicas y del procedimiento administrativo común, que, en sede de las disposiciones generales de los procedimientos administrativos, establece una exigencia elemental en garantía de la objetividad de las encuestas de opinión pública utilizadas en la instrucción de un procedimiento administrativo:

"Los resultados de los sondeos y encuestas de opinión que se incorporen a la instrucción de un procedimiento deberán reunir las garantías legalmente establecidas para estas técnicas de información, así como la identificación técnica del procedimiento seguido para la obtención de estos resultados» 51 .

Esta innovadora disposición es, sin embargo, de difícil aplicación, por lo menos en su integridad; y ello por la única y sencilla razón de que hasta el momento no se ha aprobado ninguna Ley que recoja lo que el artículo 78.2 denomina "las garantías legalmente establecidas para estas técnicas de información". Mientras esa Ley no se dicte, y por el momento no hay indicios en tal sentido, sólo podrá aplicarse la exigencia de que en el expediente administrativo en cuestión quede constancia de lo que usualmente se denomina la "ficha técnica de la encuesta" y que constituye, en cierto modo, como dice Vincenzo ZenoZencovich, "su carnet de identidad" 52 .

La Ley no determina cómo debe hacerse "la identificación técnica del procedimiento seguido", pero parece que dicha identificación deberá ser lo más detallada posible, pues en los expedientes administrativos no existen las limitaciones de espacio propias de los medios de comunicación. Deberá incluir, en cualquier caso, elementos tan relevantes como la denominación y el domicilio del organismo o entidad,

nal tratados automáticamente con ocasión de tales actividades no podrán ser utilizados con finalidad distinta ni cedidos de forma que puedan ser puestos en relación con una persona concreta". Este precepto no ha sido recogido, sin embargo, por la Ley Orgánica 15/1999, de 13 de diciembre, de protección de datos personales, que ha sustituido a la Ley de 1992.

51 Sobre este novedoso precepto legal vid. Jesús González Pérez y Francisco González Navarro, Comentarios a la Ley de Régimen Jurídico de las Administraciones Públicas y Procedimiento Administrativo Común (Ley 30/1992, de 26 de noviembre), 2.a edición, dos volúmenes, Cívitas, Madrid, 1999, vol. II, págs. 1332-1337.

52 Vid. Vincenzo ZENO-ZENCOVICH, "Sondaggi demoscopici e responsabilità civile", en la obra colectiva por él dirigida: I sondaggi..., op. cit., págs. 140-141. 
pública o privada, o de la persona física que haya realizado el sondeo, así como de la que haya encargado su realización; la descripción de la población representada o universo de referencia de la muestra, el sistema de muestreo, el tamaño de la muestra, el margen de error de la misma, su dispersión geográfica, el nivel de representatividad y el procedimiento de selección de los encuestados; la forma de recogida de la información (personal, telefónica o postal), la fecha de realización del trabajo de campo, el texto íntegro de las cuestiones planteadas y el número de personas que no han contestado a cada una de ellas. No obstante, lo mejor sería que en las disposiciones reglamentarias de desarrollo de la Ley se detallara el contenido mínimo que debe tener la ficha.

\section{C) Valoración}

¿Qué juicio merece la actual regulación de la objetividad de las encuestas de opinión pública en nuestro Ordenamiento jurídico? ¿Es la adecuada? ¿Es insuficiente o demasiado intervencionista? ¿Está bien articulada?

La respuesta ha de ser forzosamente ambivalente: de un lado, nos parece claramente positiva la decisión del legislador español de intervenir en este terreno y de hacerlo no sólo en el ámbito de las encuestas de carácter electoral, como suele suceder en el Derecho comparado, sino también en el de las encuestas utilizadas en la instrucción de un procedimiento administrativo; pero, de otro lado, ni estamos de acuerdo con alguna de las normas establecidas, ni, sobre todo, con el reducido ámbito material de la regulación. Echamos en falta la existencia de una política clara, sistemática y más ambiciosa sobre la materia que nos ocupa. Parece como si el legislador se hubiera quedado a medio de todo y que no tuviera un criterio claro sobre lo que hacer al respecto. Expresa su deseo de regular las encuestas de opinión pública en general, pero no termina de hacerlo.

A nuestro juicio, es preciso que el legislador se arme de valor $y$ dé un paso más, en garantía de la veracidad de la información en este importante terreno. El derecho constitucional a la información veraz debe protegerse en toda su extensión: en cualquier ámbito y en cualquier período de tiempo. Su relevancia institucional de cara a la creación de una opinión pública libre - sin la cual, como dice nuestro Tribunal Constitucional, "quedarían vaciados de contenido real otros derechos que la Constitución consagra, reducidas a formas hueras las 
instituciones representativas y absolutamente falseado el principio de legitimidad democrática que enuncia el artículo 1.2 de la Constitución, y que es la base de toda nuestra ordenación jurídico-política»- así lo exige 53 .

Aunque es cierto que este transcendente derecho tiene su máximo alcance en el terreno de las encuestas electorales publicadas durante el período preelectoral, $y$ en el de los procedimientos administrativos, esto no debe significar en modo alguno que fuera de estos acotados sectores deba quedar sin protección, porque desprotección y desamparo es precisamente lo que supone hoy dia confiar en la autorregulación profesional, como ya hemos tenido ocasión de poner de relieve con cierto detenimiento en un apartado anterior.

España debe volver, por tanto, a regular las encuestas de opinión pública en su integridad. No se trata, sin embargo, de restaurar al régimen jurídico previsto en el Decreto 2951/1975, de 31 de octubre, del Ministerio de Información y Turismo, sobre régimen de las empresas dedicadas a las encuestas de opinión, sino de que el Parlamento apruebe una ley específica sobre encuestas de opinión pública que tenga en cuenta tanto nuestra experiencia histórica, como la regulación actual sobre las encuestas electorales, las normas presentes en la legislación de otros países y las propuestas ideadas por la doctrina en los últimos años ${ }^{54}$.

Dicha ley, para ser más exactos, podría sujetarse a las siguientes directrices, todas ellas muy fáciles de plasmar normativamente:

1. Extender -con las adaptaciones precisas- gran parte del contenido de la regulación de las encuestas electorales actualmente vigente a todas las encuestas de opinión pública y con independencia del momento, electoral o no, en que se publiquen. Nos referimos, básicamente, a la obligación de publicar la ficha técnica de toda encuesta que se divulgue, aunque con un contenido mínimo, más reducido que el

53 Se trata de la Sentencia del Tribunal Constitucional 6/1981, de 16 de marzo, cuya doctrina ha sido posteriormente reiterada en otras muchas, como hemos visto más arriba.

54 En otros países, como Francia, que cuentan también con una regulación específica sobre publicación de encuestas electorales, existe un fuerte movimiento de opinión, tanto en el terreno político como fuera de él, favorable a extenderla al resto de los sondeos de opinión pública. Sobre el caso francés vid., entre otros, Emmanuel Derieux, "Droit et déontologie des sondages d'opinion», Trimedia, núm. 10, 1980, pág. 10. 
que exige hoy la LOREG55; a la interdicción de falsificar los datos e informaciones de los sondeos; $y$ al derecho de rectificación de las infracciones que se comentan.

2. Limitar la prohibición de publicar encuestas electorales a la mínima expresión: al día de la votación. Todo lo que vaya más allá de este breve período de tiempo tiene a nuestro juicio una difícil justificación constitucional. No se trata, conviene advertirlo, de que la prohibición de publicar encuestas electorales durante los cinco días anteriores al de la votación nos parezca dudosamente constitucional por el hecho de limitar el, para muchos, sagrado derecho a la libertad de información, sino porque consideramos que existen muy buenas razones para estimar que tal limitación carece de una justificación objetiva y razonable. La objetividad de las encuestas electorales que se publiquen durante el periodo electoral puede garantizarse de otros modos menos constrictivos y perjudiciales para los derechos de los ciudadanos ${ }^{56}$.

3. Introducir nuevas normas en garantía de la mayor objetividad de las encuestas de opinión pública. Se trataría básicamente de establecer las reglas o principios metodológicos básicos, universalmente aceptados, que deben seguir los organismos de sondeos a la hora de efectuar encuestas de opinión y de crear un Registro público de organismos que reúnan los requisitos personales y materiales

55 La ficha técnica de las encuestas electorales tiene, a nuestro juicio, un contenido excesivamente amplio, pues el espacio con que cuentan los medios de comunicación es limitado y la capacidad de captar la atención del público y de que éste comprenda el significado de lo que se le informa todavía lo es más.. El artículo 69.2 de la LOREG señala al respecto lo siguiente:

"Los realizadores de todo sondeo o encuesta deben, bajo su responsabilidad, acompañarla de las siguientes especificaciones, que asimismo debe incluir toda publicación de las mismas: a) Denominación y domicilio del organismo o entidad, pública o privada, o de la persona física que haya realizado el sondeo, así como de la que haya encargado su realización. b) Características técnicas del sondeo, que incluyan necesariamente los siguientes extremos: sistema de muestreo, tamaño de la muestra, margen de error de la misma, nivel de representatividad, procedimiento de selección de los encuestados y fecha de realización del trabajo de campo. c) Texto íntegro de las cuestiones planteadas y número de personas que no han contestado a cada una de ellas."

56 Vid. Luis Gálvez Muñoz, "La prohibición de difundir encuestas electorales: ¿una norma inconstitucional?, Revista de las Cortes Generales, núm. 41, 1997, págs. 45-89. Otros autores se muestran, en cambio, a favor de ampliar la prohibición temporal de publicación de encuestas electorales. En este sentido vid. Enrique Arnaldo Alcubilla, "Procesos electorales y opinión pública», Revista de las Cortes Generales, núm. 34, 1995, pág. 189. 
necesarios para efectuar las encuestas con rigor científico y seriedad profesional, informándose en la ficha técnica de la encuesta si la empresa que lo ha realizado está o no inscrita en tal Registro ${ }^{57}$.

4. Instaurar un nuevo organismo de carácter público encargado especificamente de velar por el cumplimiento de las normas relativas a las encuestas de opinión pública, tal y como han hecho Francia y Bélgica con la llamada Commission des Sondages. El control de este órgano se extendería a todas las encuestas de opinión, electorales o no, aunque no habría graves objeciones a la posibilidad de que la Junta Electoral Central siguiera encargándose del control de las encuestas electorales o, al menos, de la infracción de la prohibición temporal de su difusión ${ }^{58}$.

57 Por ejemplo, que la muestra de la encuesta deba ser representativa del conjunto de la población a que se refiere, o que las preguntas a los encuestados deban formularse con claridad y precisión y sin orientar el sentido de las respuestas.

58 Portugal ofrece un ejemplo de reparto de competencias en las tareas de control $y$, además, en relación con una misma clase de encuestas, las electorales. El control sobre esta regulación se reparte entre la Alta Autoridad para la Comunicación Audiovisual y la Comisión Electoral Nacional. La primera se ocupa de «comprobar las condiciones de realización de los sondeos y encuestas de opinión, así como el rigor y la objetividad de las publicación de sus resultados"; y la segunda de "supervisar" el cumplimiento de la prohibición temporal de publicar encuestas de opinión directa o indirectamente relacionados con actos electorales o referendos (artículo 9 de la Ley núm. 31/1991, de 20 de julio, sobre publicación y difusión de sondeos y encuestas de opinión). 